\title{
Clinico- bacteriological profile of Community Acquired Pneumonia (CAP) in children aged 3-59 months: A cross sectional study
}

\author{
Manoj Kumar Singh', Sheo Pratap Singh², Rajesh Kumar ${ }^{3}$ Pankaj Kumar ${ }^{4}$, Jafar Suhail ${ }^{5}$, \\ Rajeshwar Dayal ${ }^{6}$, Madhu Nayak ${ }^{7}$, Arti Agarwal ${ }^{8}$ \\ ${ }^{1}$ Associate Professor and Head, Department of Paediatrics, Government Medical College, Banda, Uttar Pradesh,India \\ ${ }^{2}$ Assistant Professor, ${ }^{5}$ Resident, ${ }^{6}$ Professor and Head, ${ }^{7}$ Assistant Professor, Department of Paediatrics, S N Medical \\ College, Agra, Uttar Pradesh, India, ${ }^{3}$ Professor and Head, Government Medical College, Department of Paediatrics, \\ Azamgarh, Uttar Pradesh,India, ${ }^{4}$ Associate Professor and Head, Department of Paediatrics, Government Medical \\ College, Saharanpur, Uttar Pradesh, India, ${ }^{8}$ Assistant Professor, Department of Microbiology, SN Medical College, Agra, \\ Uttar Pradesh, India
}

A B S T R A C T

Background: Worldwide community-acquired pneumonia (CAP) is the major cause of high mortality among under five children in India. After introduction of Pneumococcal and $\mathrm{H}$. influenzae vaccination there is paucity of data regarding etiological profile of pneumonia. Aims and Objective: To evaluate the Clinico- epidemiological profile and etiology of community acquired pneumonia in children. Materials and Methods: We enrolled children aged 3-59 months with CAP (based on WHO criteria of tachypnea with cough or breathing difficulty) over 18 months and recorded presenting symptoms, clinical signs and chest radiography. We performed blood and nasopharyngeal swab (NPS) bacterial culture simultaneously to detect etiological agent of community acquired pneumonia in children. Results: Out of 150 cases of CAP, $90 \%$ of caeses had cough and fever and nearly 80$90 \%$ cases had tachypnea and crackles on examination. Radiological findings suggestive of pneumonia was seen in $86 \%$ cases. Most common organism isolated was $S$ aureus in both NPS culture (18.7\%) and blood culture ( $14.7 \%)$.Other common organisms detected in NPS culture were S pneumoniae (6\%), E Coli (4.7\%), Klebsiella (4.7\%), CONS (3.3\%), and Pseudomonas $(2.7 \%)$. In blood culture the common organism detected after $S$ aureus was E coli (5.3\%), S pneumoniae (3.3\%), Klebsiella (3.3\%), CONS( $3.8 \%)$, and Pseudomonas $(2.5 \%)$. Conclusions: We observed that $\mathrm{S}$ aureus was the predominant etiological organism isolated in both blood and nasopharyngeal swab bacterial culture in patients suffering from community-acquired pneumonia.

Key words: Blood culture; Community acquired pneumonia; Nasopharyngeal swab; $S$ aureus

\section{INTRODUCTION}

Pneumonia is an inflammation of the lung parenchyma usually caused by microorganisms, however noninfectious causes include aspiration of food or gastric acid, foreign bodies, hydrocarbons, hypersensitivity reactions and drug or radiation induced pneumonitis. Common bacterial agents causing pneumonia in children under 5 year includes Klebsiella, Escherichia coli(E coli), Hemophilus influenzae (H influenzae),
Streptococcus pneumoniae (S pneumoniae) and Staphylococcus aureus (S aureus). ${ }^{1}$ World health organization(WHO) has defined pneumonia on the basis of clinical features obtained from visual inspection and respiratory rate (RR). ${ }^{2}$ Acute lower respiratory tract infection (LRTI) is the leading cause of death in children less than 5 years of age. It is estimated that there were more than 120 million episodes of pneumonia among children less than five years of age during 2010-11, out of which over $10 \%$ were severe episodes. ${ }^{3}$ According 
to UNICEF (2018) under-five mortality rate in India is 36.5 per thousand live births. ${ }^{4}$ Out of this, pneumonia accounts for $14.6 \%$ deaths. Incidence of childhood pneumonia in terms of episodes per child per year in India is $0.36 .{ }^{5}$ Statewise, Uttar Pradesh accounts for the highest number of community acquired pneumonia (CAP) cases as well as deaths (cases- $24 \%$, deaths- $26 \%$ ) in children $<5$ years of age followed by Bihar (cases- $16 \%$, deaths- $22 \%$ ), Madhya Pradesh (cases- $9 \%$, deaths-12\%) \& Rajasthan (cases- $8 \%$, deaths- $11 \%){ }^{6}$

There is paucity of data regarding etiological diagnosis of pneumonia from western UP. Introduction of Pneumococcal and Hemophilus influenzae in Universal immunization programme might also affect present etiological profile of community acquired pneumonia. Identification of etiological agent will also help us to select appropriate antibiotics and will prevent indiscriminate use of antibiotics and resistance. Hence his study was aimed to find the Clinico- epidemiological profile and etiology of community acquired pneumonia in children.

\section{MATERIALS AND METHODS}

This cross sectional study conducted over a period of 18 months in department of Pediatrics, S N Medical College, Agra(SNMC).Children in the age group of 3-59 months with signs and symptoms suggestive of Community acquired pneumonia like cough, tachypnoea with or without chest indrawing and general danger signs like not able to drink, persistent vomiting, convulsions, lethargic or unconscious, stridor in a calm child or severe malnutrition were included in the study. ${ }^{7}$ Children with history of hospitalization for more than 48 hours in the last 2 weeks, children on antibiotic therapy for more than 48 hours prior to admission, and children diagnosed with bronchial asthma, bronchiolitis on clinical or radiological basis and those with underlying chronic conditions like HIV were excluded. An informed consent was taken from patient's attendant before enrolling the patient in the study. After completing detailed history and clinical examination, patients were classified in to two groups Group A (Age 3 months to 12 months) and Group B (Age 13 months to 59 months). Assessment of pneumonia severity was based on WHO classification. ${ }^{7}$ All children underwent chest radiography and classified as per WHO guidelines into three categories (a) No consolidation, infiltrate or effusion, (b) Other infiltrates (consolidation, infiltration or effusion), (c) Primary endpoint pneumonia. Anthropometry and immunization status were also noted.

Nasopharangeal swab (NPS) for culture was collected from all study subjects. Patient was made to sit with head against a wall during this procedure. A sterile Hiculture skim milk tryptone glucose glycerine medium (STGG) swab stick on flexible shaft supplied by Himedia laboratories private limited was inserted into one nostril straight back and continued along the floor of the nasal passage for several centimetres until reaching the nasopharynx. Swab was rotated 180 degrees to saturate the swab and then removed immediately, inoculated into a vial containing STGG media and the shaft was cut with scissors. The lid on the vial was replaced leaving the swab in STGG media. NPS in STGG vial was labeled and vortexed so that all the bacteria came into the suspension \& kept at a temperature between $5-25^{\circ} \mathrm{C}$ as prescribed by the manufacturer. ${ }^{8,9}$ Sample was then transported within one hour to the Microbiology department, S.N. Medical College Agra for further processing maintaining a temperature of $5-25^{\circ} \mathrm{C}$. Blood was collected from all patients by venipuncture. Standard procedure for venipuncture was employed with particular attention to minimize risk of contamination of blood cultures. All the NP swabs and blood culture vials ran through conventional culture technique using blood agar, chocolate agar \& MacConkey agar. The study protocol was approved by the ethical committee of the institute.

\section{RESULTS}

A total of 150 patients fulfilling the inclusion criteria were enrolled in the study. Median age of the patients was 12 months, $82(54.7 \%)$ patients were male and 68 (45.3\%) were female. Severe acute malnutrition was observed in $82(54.7 \%)$ patient,11 (7.3\%) were not immunized and $57(38 \%)$ were partially immunized as per National immunization schedule (Table 1).

Common symptoms in decreasing order of frequency were cough $(90.7 \%)$, fever $(88 \%)$, difficulty in breathing $(81.3 \%)$ and refusal to feed $(41.3 \%)$. The other atypical symptoms were convulsion, abdominal/chest pain, regurgitation of feed and vomiting. The common signs were crackles present in $92 \%$ patients followed by tachypnea (81.3\%), subcostal retraction $(54 \%)$, cyanosis $(10 \%)$ and wheezing $(8 \%)$. Consolidation/Infiltrates $(57.3 \%)$ were the most common radiological finding followed by primary end point pneumonia and no consolidation/infiltrate or effusion. Out of 150 children, a total of $103(68.7 \%)$ were diagnosed with severe pneumonia and $47(31.3 \%)$ with pneumonia (Table 2).

NPS culture was positive in $60(40 \%)$ cases and blood culture in $47(31.33 \%)$ cases. In this study, a higher percentage of group A patients (46.3\%) showed growth in NPS culture while only $34.3 \%$ of group B patients showed growth in NPS culture. Most common organism isolated was $S$ aureus 
both in NPS culture (18.7\%) and blood culture (14.7\%). Other common organism detected in NPS culture were S pneumonia (6\%), Ecoli(4.7\%), Klebsiella (4.7\%), Coagulase negative Staphylococci (CONS) (3.3\%) and Pseudomonas (2.7\%). In blood culture the common organism detected after $S$ aureus were E coli (5.3\%), S pneumoniae (3.3\%), Klebsiella $(3.3 \%)$, CONS $(3.8 \%)$ and Pseudomonas (2.5\%). In this

\begin{tabular}{|c|c|c|}
\hline & Number (N) & Percentage (\%) \\
\hline \multicolumn{3}{|l|}{ Age Group } \\
\hline 3-12 months & 80 & 53.0 \\
\hline $13-59$ months & 70 & 47.0 \\
\hline \multicolumn{3}{|l|}{ Gender } \\
\hline Male & 82 & 54.7 \\
\hline Female & 68 & 45.3 \\
\hline \multicolumn{3}{|l|}{ Co-morbidity } \\
\hline Malnutrition & 82 & 54.7 \\
\hline \multicolumn{3}{|l|}{ Immunization Status } \\
\hline Immunized & 82 & 54.7 \\
\hline Partially Immunized & 57 & 38.0 \\
\hline Not Immunized & 11 & 7.3 \\
\hline
\end{tabular}

\begin{tabular}{|c|c|c|}
\hline & Number & Percentage \\
\hline \multicolumn{3}{|l|}{ Symptoms } \\
\hline Cough & 136 & $90.7 \%$ \\
\hline Fever & 132 & $88.0 \%$ \\
\hline Difficult breathing & 122 & $81.3 \%$ \\
\hline Refusal to feed & 65 & $41.3 \%$ \\
\hline \multicolumn{3}{|l|}{ Signs } \\
\hline Tachypnea & 122 & $81.3 \%$ \\
\hline Crackles & 138 & $92.0 \%$ \\
\hline Wheezing & 12 & $8.0 \%$ \\
\hline Subcostal Retraction & 81 & $54.0 \%$ \\
\hline Cyanosis & 15 & $10.0 \%$ \\
\hline \multicolumn{3}{|l|}{ Radiological Finding } \\
\hline No consolidation/ infiltrate/ effusion & 21 & $14.0 \%$ \\
\hline Other infiltrate & 86 & $57.3 \%$ \\
\hline Primary end point pneumonia & 43 & $28.7 \%$ \\
\hline \multicolumn{3}{|l|}{ Severity } \\
\hline Pneumonia & 47 & $31.3 \%$ \\
\hline Severe Pneumonia & 103 & $68.7 \%$ \\
\hline
\end{tabular}

study $S$ aureus was the most common organism isolated as common, in both NPS and blood culture of the same patient in 7 (4.7\%) patients, followed by E coli and CONS with overall presence in $2(1.3 \%$ ) patients (Table 3$)$.

\section{DISCUSSION}

Community acquired pneumonia is a major public health problem in India, especially in Uttar Pradesh. In spite of all the improvements made in immunization coverage, diagnostic modalities and treatment, pneumonia continues to be a major health problem and contributes significantly to morbidity and mortality.

Age is an important predictor of morbidity and mortality in pneumonias. In this study, the proportion of cases of severe pneumonia was higher in group A patients $(73.7 \%)$ than in group B $(62.9 \%)$. These findings were in concordance with other studies in India. ${ }^{10,11}$ The male $(54.7 \%$ ) outweighs the females $68(45.3 \%)$, with male: female ratio of 1.21. Higher prevalence of pneumonia in males had also been reported in other studies. ${ }^{12,13}$ Majority of patients of pneumonia were malnourished and it was observed in $82(54.7 \%)$,we found that severe pneumonia was present in $73.3 \%$ of patients having severe acute malnutrition. Similar observation were found in several other studies. ${ }^{14-16}$

In present study cough $(90.7 \%)$, fever $(88 \%)$, difficulty in breathing $(81.3 \%)$ and refusal to feed $(41.3 \%)$ were the common clinical features. Almost similar clinical features were reported by Shekhawat et al and Juvén et al. ${ }^{17,18}$

In NPS culture, growth was detected in $40 \%$ patients in present study. A higher percentage of group A patients (46.3\%) showed growth in NPS culture while only $34.3 \%$ of group B patients showed growth in NPS culture. Higher proportion of NPS culture in younger children was seen in several other studies. ${ }^{19-21}$ In our study, $S$ aureus $(18.7 \%)$ was the most common organism isolated in both age groups with a higher proportion in younger patients.

Table 3: Distribution of organisms isolated in NPS culture and blood culture.

\begin{tabular}{|c|c|c|c|c|c|c|c|c|c|}
\hline \multirow[t]{2}{*}{ Organism } & \multicolumn{3}{|c|}{ NPS Culture(60/150) } & \multicolumn{3}{|c|}{ Blood Culture(47/150) } & \multicolumn{3}{|c|}{$\begin{array}{c}\text { NPS Culture and blood culture } \\
\text { in same patient }\end{array}$} \\
\hline & $\begin{array}{l}\text { Total } \\
\text { No }(\%)\end{array}$ & $\begin{array}{l}\text { Group A* } \\
\text { No. }(\%)\end{array}$ & $\begin{array}{l}\text { Group B** } \\
\text { No (\%) }\end{array}$ & $\begin{array}{l}\text { Total No. } \\
(\%)\end{array}$ & $\begin{array}{l}\text { Group A } \\
\text { No.(\%) }\end{array}$ & $\begin{array}{l}\text { Group B } \\
\text { No }(\%)\end{array}$ & $\begin{array}{l}\text { Total } \\
\text { No. }(\%)\end{array}$ & $\begin{array}{l}\text { Group A. } \\
\text { No }(\%)\end{array}$ & $\begin{array}{l}\text { Group B. } \\
\text { No }(\%)\end{array}$ \\
\hline S aureus & $28(18.7)$ & $16(20.0)$ & $12(17.1)$ & $22(14.7)$ & $11(13.8)$ & $11(15.7)$ & $7(4.7)$ & $4(5.0)$ & $3(4.3)$ \\
\hline S pneumoniae & $9(6.0)$ & $6(7.5)$ & $3(4.3)$ & $5(3.3)$ & $3(3.8)$ & $2(2.9)$ & $1(0.6)$ & $1(1.3)$ & 0 \\
\hline E coli & $7(4.7)$ & $5(6.3)$ & $2(2.9)$ & $8(5.3)$ & $6(7.5)$ & $2(2.9)$ & $2(1.3)$ & $1(1.3)$ & $1(1.4)$ \\
\hline Klebsiella & $7(4.7)$ & $4(5.0)$ & $3(4.3)$ & $5(3.3)$ & $4(5.0)$ & $1(1.4)$ & $1(0.6)$ & 0 & $1(1.4)$ \\
\hline $\begin{array}{l}\text { Coagulase negative } \\
\text { Staphylococci (CONS) }\end{array}$ & $5(3.3)$ & $3(3.8)$ & $2(2.9)$ & $4(2.7)$ & $3(3.8)$ & $1(1.4)$ & $2(1.3)$ & $1(1.3)$ & $1(1.4)$ \\
\hline Pseudomonas & $4(2.7)$ & $2(2.5)$ & $2(2.9)$ & $3(2.0)$ & $2(2.5)$ & $1(1.4)$ & 0 & 0 & 0 \\
\hline
\end{tabular}


Other common organism detected in NPS culture were $S$ pneumonia (6\%), E coli (4.7\%), Klebsiella (4.7\%), CONS $(3.3 \%)$ and Pseudomonas $(2.7 \%)$ in decreasing frequency. Findings in our study was different from the study done by Mathew et al who found $S$ pneumoniae as the most common organism $(255 / 2323 ; 10.97 \%)$ in nasopharyngeal specimens followed by $H$ influenzae $(31 / 2323 ; 1.33 \%)$ \& $S$ aureus $(22 / 2323 ; 0.95 \%){ }^{22}$ This can be attributed to the introduction of the pentavalent vaccine and H influenzae vaccine in the universal immunization programme in our country. The most common organism detected in blood culture in this study was $S$ aureus $(14.7 \%$ ) followed by $E$ coli (5.3\%), S pneumoniae (3.3\%), Klebsiella (3.3\%), CONS (3.8\%) and Pseudomonas (2.5\%)s. Mathew etal also found $S$ aureus as the most common organism in blood culture specimens followed by $S$ pneumonia and Klebsiella in his study. ${ }^{22}$ In another study done by Shekhawat etal also detected $S$ aureus in $10.0 \%$ cases, as the most common organism followed by $S$ pneumoniae and Pseudomonas in $3.1 \%$ cases each. ${ }^{17} S$ aureus was the most common organism isolated as common, in both NPS and blood culture of the same patient (4.7\%), followed by E coli and CONS.

\section{CONCLUSION}

$S$ aureus was the most common organism isolated in present study. Inclusion of pentavalent vaccine in universal immunization programme may be the cause of change in etiological profile of pneumonia in under 5 children. Further studies with larger sample size are required to validate our findings.

\section{REFERENCES}

1. Dublish S, Singh V. Pneumonia. In: Gupta P, Menon PSN, Ramji S, Rakesh L,eds. PG Text book of Pediatrics. $2^{\text {nd }}$ Edition. New Delhi: JAYPEE Publishers; 2018. P. 2033-2034.

2. Technical basis for $\mathrm{WHO}$ recommendations on the management of pneumonia in children at first level health facilities. WHO/ ARI/ 91.20 Geneva: World Health Organization,1991. https://apps. who.int/iris/bitstream/handle/10665/61199/WHO_ARI_91.20. pdf? sequence=1. Accessed on September 21, 2019.

3. Walker CL, Rudan I, Liu L, Nair H, Theodoratou E, Bhutta ZA, et al. Global burden of childhood pneumonia and diarrhoea. The Lancet. 2013 Apr; 381(9875):1405-1416.

https://doi.org/10.1016/S0140-6736(13)60222-6

4. Child mortality figures by region and country. WHO/UNICEF: Levels and trends in child mortality report 2018;p.32. https:// www.who.int/ maternal_child_adolescent/documents/ levels trends_child_mortality_2018/en/ Accessed on September 21, 2019.

5. Wardlaw T, Salama P, White Johansson EW and Mason E. Pneumonia: the leading killer of children. The Lancet. 2006 Sep; 368(9541):1048-1050.

https://doi.org/10.1016/S0140-6736(06)69334-3

6. Farooqui H, Jit M, Heymann DL and Zodpey S. Burden of severe pneumonia, pneumococcal pneumonia and pneumonia deaths in Indian States: modelling based estimates. PLoS One. 2015; 10(6):e0129191.

https://doi.org/10.1371/journal.pone.0129191

7. World Health Organization. Revised WHO classification and treatment of pneumonia in children at health facilities: evidence summaries. Available on https://apps.who.int/iris/ bitstream/ handle/ 10665/137319/9789241507813_eng. pdf?sequence=1\& isAllowed=y. Accessed on September 21,2019.

8. Gov.mb.ca. 2018 Available on https://www.gov.mb.ca/health/ publichealth/cpl/docs/nasopharyngeal_collection.pdf. accessed on September 21,2019

9. Tenenbaum T, Franz A, Neuhausen N, Willems R, Brade J, Schweitzer-Krantz S, et al. Clinical characteristics of children with lower respiratory tract infections are dependent on the carriage of specific pathogens in the nasopharynx. European journal of clinical microbiology \& infectious diseases. 2012;31(11):3173-3182. https://doi.org/10.1007/s10096-012-1682-y

10. Madhusudhan K, Sreenivasaiah B, Kalivela S, Nadavapalli SS and Jampana VR. Clinical and bacterial profile of pneumonia in 2 months to 5 years age children: a prospective study done in a tertiary care hospital. International Journal of Contemporary Pediatrics. 2017;4(1):90-95.

https://doi.org/10.18203/2349-3291.ijcp20163980

11. Shukla O, Dave R and Doshi RP. Clinical and microbiological profile of pneumonia in severe acute malnourished children. International Journal of Research in Medical Sciences. 2017,20;5(3):1078-1083. https://doi.org/10.18203/2320-6012.jirms20170665

12. Srivastava P, Mishra AK and Roy AK. Predisposing Factors of Community Acquired Pneumonia in Under-Five Children. Lung Dis Treat. 2015; 1(1): 1 https://doi.org/10.4172/2472-1018.1000101

13. Bowen SJ and Thomson AH. British Thoracic Society Paediatric Pneumonia Audit: a review of 3 years of data. Thorax. 2013;68(7):682-683.

https://doi.org/10.1136/thoraxjnl-2012-203026

14. Da Fonseca Lima EJ, Mello MJ, Lopes MI, Serra GH, Lima DE and Correia JB. Risk factors for community-acquired pneumonia in children under five years of age in the post-pneumococcal conjugate vaccine era in Brazil: a case control study. BMC pediatrics. 2016;16(1):157.

https://doi.org/10.1186/s12887-016-0695-6

15. Goel K, Ahmad S, Agarwal G, Goel P and Kumar V. A cross sectional study on prevalence of acute respiratory infections (ARI) in under-five children of Meerut District. India. J Comm Med Health Educ. 2012;2(9):176.

https://doi.org/10.4172/2161-0711.1000176

16. Cunha AL. Relationship between acute respiratory infection and malnutrition in children under 5 years of age. Acta Paediatrica. $2000 ; 89(5): 608-9$.

https://doi.org/10.1080/080352500750027943

17. Shekhawat $Y S$, Sharma $P$, Singh A and Payal V. Bacteriological and clinical profile of community acquired pneumonia in hospitalised children with associated co-morbidity in a tertiary care centre of Western Rajasthan, India. International Journal of Contemporary Pediatrics. 2016;3(4):1380-1384.

https://doi.org/10.18203/2349-3291.ijcp20163682

18. Juven T, Ruuskanen $O$ and Mertsola J. Symptoms and signs of community-acquired pneumonia in children. Scandinavian journal of primary health care. 2003;21(1):52-56. https://doi.org/10.1080/02813430310000573

19. Lu AZ, Shi P, Wang LB, Qian LL and Zhang XB. Diagnostic value 
of nasopharyngeal aspirates in children with lower respiratory tract infections. Chinese medical journal. 2017;130(6):647-651. https://doi.org/10.4103/0366-6999.201595

20. Adetifa IM, Antonio M, Okoromah CA, Ebruke C, Inem V Nsekpong D, etal. Adegbola RA. Pre-vaccination nasopharyngeal pneumococcal carriage in a Nigerian population: epidemiology and population biology. PloS one. 2012;7(1):e30548.

https://doi.org/10.1371/journal.pone.0030548

21. Hill PC, Akisanya A, Sankareh K, Cheung YB, Saaka M, Lahai G, et al. Nasopharyngeal carriage of Streptococcus pneumoniae in Gambian villagers. Clinical infectious diseases. 2006;43(6):673-679. https://doi.org/10.1086/506941

22. Mathew JL, Patwari AK, Gupta P, Shah D, Gera T, Gogia S, et al. Acute respiratory infection and pneumonia in India: a systematic review of literature for advocacy and action: UNICEF-PHFI series on newborn and child health, India. Indian pediatrics. 2011;48(3):191.

https://doi.org/10.1007/s13312-011-0051-8

Author's contribution:

MS,PK,SP- Concept and design of study; RK,RD,MN- Supervised data collection and Litreture review; ZS, SP-Data collection, analysis and first draft of manuscript; MS,PK- Statistical analysis, interpretation of resuts and final draft of manuscript; AA- Litreture review and interpretation of lab results.

Work attributed to:

SN Medical College, Agra,Uttar Pradesh,India.

Orcid ID:

Dr. Manoj Kumar Singh- (1) https://orcid.org/0000-0002-7822-9142

Dr. Sheo Pratap Singh- (i) https://orcid org/0000-0003-4244-8244

Dr. Rajesh Kumar- io https://orcid.org/0000-0001-8978-7097

Dr. Pankaj Kumar- (i) https://orcid.org/0000-0002-5038-2954

Dr. Jafar Suhail- (io https://orcid.org/0000-0001-8686-1378

Dr. Rajeshwar Dayal- (1) https://orcid.org/0000-0003-0030-4509

Dr. Madhu Nayak- (i) https://orcid.org/0000-0001-9700-3854

Dr. Arti Agarwal- (i) https://orcid.org/0000-0002-0983-4189

Source of Funding: None, Conflict of Intrest: None. 